Louisiana State University

LSU Digital Commons

Faculty Publications

Department of Physics \& Astronomy

2-18-2013

\title{
Evidence of martensitic phase transitions in magnetic Ni-Mn-In thin films
}

A. Sokolov

University of Nebraska-Lincoln

Le Zhang

University of Nebraska-Lincoln

I. Dubenko

Southern Illinois University Carbondale

T. Samanta

Southern Illinois University Carbondale

S. Stadler

Louisiana State University

See next page for additional authors

Follow this and additional works at: https://digitalcommons.Isu.edu/physics_astronomy_pubs

\section{Recommended Citation}

Sokolov, A., Zhang, L., Dubenko, I., Samanta, T., Stadler, S., \& Ali, N. (2013). Evidence of martensitic phase transitions in magnetic Ni-Mn-In thin films. Applied Physics Letters, 102 (7) https://doi.org/10.1063/

1.4793421

This Article is brought to you for free and open access by the Department of Physics \& Astronomy at LSU Digital Commons. It has been accepted for inclusion in Faculty Publications by an authorized administrator of LSU Digital Commons. For more information, please contact ir@lsu.edu. 


\section{Authors}

A. Sokolov, Le Zhang, I. Dubenko, T. Samanta, S. Stadler, and N. Ali 


\title{
Southern Illinois University Carbondale OpenSIUC
}

$2-2013$

\section{Evidence of Martensitic Phase Transitions in Magnetic Ni-Mn-In Thin Films}

\author{
A. Sokolov \\ Le Zhang \\ Igor Dubenko \\ Southern Illinois University Carbondale \\ Tampas Samanta \\ Southern Illinois University Carbondale \\ Shane Stadler \\ Southern Illinois University Carbondale \\ See next page for additional authors
}

Follow this and additional works at: http://opensiuc.lib.siu.edu/phys_pubs

(C) 2013 American Institute of Physics

Published in Applied Physics Letters, Vol. 102 No. 072407 (2013) at doi: 10.1063/1.4793421

\section{Recommended Citation}

Sokolov, A., Zhang, Le, Dubenko, Igor, Samanta, Tampas, Stadler, Shane and Ali, Naushad. "Evidence of Martensitic Phase Transitions in Magnetic Ni-Mn-In Thin Films." (Feb 2013).

This Article is brought to you for free and open access by the Department of Physics at OpenSIUC. It has been accepted for inclusion in Publications by an authorized administrator of OpenSIUC. For more information, please contact opensiuc@lib.siu.edu. 
Authors

A. Sokolov, Le Zhang, Igor Dubenko, Tampas Samanta, Shane Stadler, and Naushad Ali 


\title{
Evidence of martensitic phase transitions in magnetic Ni-Mn-In thin films
}

\author{
A. Sokolov, ${ }^{1}$ Le Zhang, ${ }^{1}$ I. Dubenko, ${ }^{2}$ T. Samanta, ${ }^{2}$ S. Stadler, ${ }^{3}$ and N. Ali ${ }^{2}$ \\ ${ }^{1}$ UNL Department of Physics and Astronomy, Nebraska 68588, USA \\ ${ }^{2}$ Department of Physics, Southern Illinois University, Carbondale, Illinois 62901, USA \\ ${ }^{3}$ Department of Physics and Astronomy, Louisiana State University, Baton Rouge, Louisiana 70803, USA
}

(Received 19 November 2012; accepted 11 February 2013; published online 21 February 2013)

\begin{abstract}
$\mathrm{Ni}_{50} \mathrm{Mn}_{35} \mathrm{In}_{15}$ Heusler alloy thin films (with thicknesses of about $10 \mathrm{~nm}$ ) have been grown on single crystal $\mathrm{MgO}$ and $\mathrm{SrTiO}_{3}$ (STO) (100) substrates using a laser-assisted molecular beam epitaxy method. Films of mixed austenitic and martensitic phases and of pure martensitic phase have been detected for those grown on $\mathrm{MgO}$ and STO substrates, respectively. Thermomagnetic curves were measured using a SQUID magnetometer and are consistent with those of off-stoichiometric In-based bulk Heusler alloys, including a martensitic transition at $\mathrm{T}=315 \mathrm{~K}$ for films grown on $\mathrm{MgO}$. The differences in the properties of the films grown on $\mathrm{MgO}$ and STO are discussed. (C) 2013 American Institute of Physics. [http://dx.doi.org/10.1063/1.4793421]
\end{abstract}

Heusler alloys are receiving increasing attention from both the magnetism and material science communities due to their large variety of magnetoresponsive effects, ${ }^{1,2}$ such as magnetic shape memory/strain, ${ }^{3,4}$ large magnetoresistance, ${ }^{5,6}$ anomalous Hall, ${ }^{7}$ and magnetocaloric effects. ${ }^{8-10}$ This interest has been stimulated by their potential technological applications in the field of magnetic actuators, ${ }^{11}$ sensors, ${ }^{12}$ energy-harvesting devices, ${ }^{13}$ and solid-state magnetic refrigeration. ${ }^{14}$ The broad spectrum of properties of these materials is mainly attributed to the specific type of structural instability known as a martensitic transformation observed in these compounds. This instability is described as a temperature-induced first-order structural phase transition from a high-temperature austenitic phase (AP: cubic $\mathrm{L} 2_{1}$ or B2 crystal structure) to a low-temperature martensitic phase (MP) and characterized by a crystal cell of lower symmetry (tetragonal, modulated orthorhombic, or monoclinic). ${ }^{15}$ While a vast majority of reported results have dealt with bulk shape-memory Ni-Mn-Ga or Ni-Mn-In alloys, for many electronic applications, it would be extremely desirable to synthesize such materials (with corresponding properties) in thin film form. Various approaches have been undertaken in an attempt to fabricate films: flash-evaporation of alloy powders, ${ }^{16}$ thermal co-evaporation, ${ }^{17}$ molecular beam epitaxy (MBE) ${ }^{18}$ and pulsed laser deposition (PLD). ${ }^{19,20}$ However, the fabrication of films with desirable characteristics remains a technological challenge. The successful synthesis of epitaxial Ni-Co-Mn-In Heusler alloy with the characteristic behavior of bulk alloys has been recently reported by Niemann et al..$^{21,22}$ The result was obtained by sputtering from a pre-synthesized target onto a $\mathrm{MgO}$ substrate with an epitaxial chromium seed layer. It has been shown that a relatively high substrate temperature $\left(\sim 400^{\circ} \mathrm{C}\right)$ is required for proper chemical order formation of the Heusler alloy. However, argon bombardment of the target resulted in differing sputtering rates of constituent materials (i.e., non-congruent transfer) and the evidence of composition deviation with time were reported. On the other hand, while a $\mathrm{Cr}$ seed layer apparently promotes epitaxial growth on $\mathrm{MgO}$ substrates, for many applications, which take advantage of unique transport properties of Heusler alloys, the use of metallic buffer layer should be avoided. In order to provide high quality growth with low defect density, the identification of a suitable substrate material is critical. One of the decisive parameters is the lattice constant of the substrate, which should closely match the parameters of the film. However, since the structural martensitic transition is accompanied by a drastic change in lattice parameters, as-grown films may experience a kinetic arrest, ${ }^{23}$ where the martensitic transformation is interrupted. Thus, the impact of the substrate on the martensite transformation should be clarified.

In this Letter, we report on the growth and characterization of compressive and nearly zero strained Ni-Mn-In thin films grown on $\mathrm{SrTiO}_{3}$ (STO) and $\mathrm{MgO}$ single crystal substrates from a $\mathrm{Ni}_{50} \mathrm{Mn}_{35} \mathrm{In}_{15}$ target of nominal composition. The off-stochiometric $\mathrm{Ni}_{50} \mathrm{Mn}_{35} \mathrm{In}_{15}$ alloy has been selected as a target since the martensitic transition observed in the bulk material is very close to ambient temperature and is therefore of practical importance. ${ }^{9,10}$ The effect of induced strain on the resulting crystal structures and magnetic properties is discussed.

We employed a laser-assisted molecular beam epitaxy (LMBE) method as the most reliable for the congruent transfer of the target constituents. The $\mathrm{Ni}_{50} \mathrm{Mn}_{35} \mathrm{In}_{15}$ target was fabricated by conventional arc-melting in a high-purity argon atmosphere using $4 \mathrm{~N}$ purity elements and was annealed in high vacuum $\left(\approx 10^{-4}\right.$ Torr $)$ for $24 \mathrm{~h}$ at $850^{\circ} \mathrm{C}$. Laser ablation was performed using $\mathrm{KrF}$ excimer laser $(248 \mathrm{~nm})$ with an energy density of $4 \mathrm{~J} / \mathrm{cm}^{2}$ under high vacuum conditions (better then $10^{-8}$ Torr) and a $10 \mathrm{~Hz}$ repetition rate. The substrate temperature was held at $150{ }^{\circ} \mathrm{C}$ for the STO substrate and at ambient temperature for the $\mathrm{MgO}$ substrate. Film thicknesses were calibrated per laser pulse by an x-ray reflectivity method. The resulting phase compositions and unit cell parameters of the samples were determined by x-ray powder diffraction using the single crystal substrates as an internal standard. Thermomagnetic curves $\mathrm{M}(\mathrm{H}, \mathrm{T})$ were measured using a Superconducting Quantum Interference Device (SQUID) magnetometer (Quantum Design). The temperature dependencies of $\mathrm{M}(\mathrm{T})$ have been obtained during heating at $\mathrm{H}=500 \mathrm{Oe}$ after the samples were cooled to $5 \mathrm{~K}$ in zero magnetic field (FC) and during cooling from $\mathrm{T}=380 \mathrm{~K}$ at $\mathrm{H}=500 \mathrm{Oe}$ (FCC).

A typical AFM image of the film surface with up to $10 \mathrm{~nm}$ thickness is shown in Fig. 1 for the case of the STO 

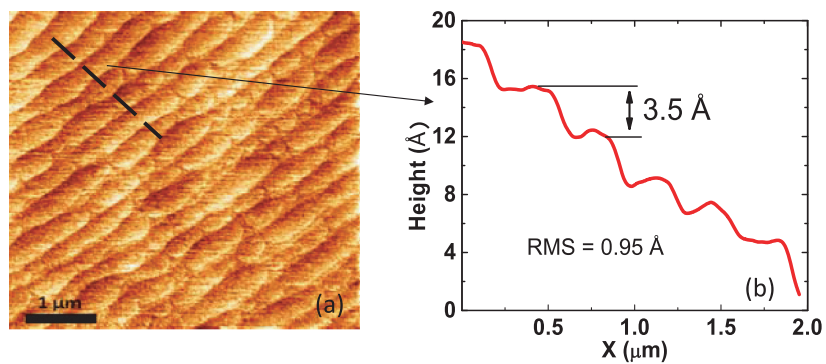

FIG. 1. AFM image (a) and line scan profile (b) of a $10 \mathrm{~nm} \mathrm{Ni} \mathrm{Ni}_{50} \mathrm{Mn}_{35} \mathrm{In}_{15}$ thin film on a $\mathrm{SrTiO}_{3}\langle 100\rangle$ single crystal substrate. Estimated roughness on the terrace surfaces is about $95 \mathrm{pm}$, and the step heights close to that of the STO unit cell parameter $(0.3905 \mathrm{~nm})$.

substrate. As clearly seen, the step structure of the substrate is still preserved for this film thickness, with typical step heights corresponding to the STO unit cell parameter of $0.39 \mathrm{~nm}$. The roughness on the terrace surfaces is limited to $0.15 \mathrm{~nm}$, indicating an atomically smooth layer, hence suggesting a Frank-van der Merwe (FM: layer-by-layer) initial growth mode. As the thickness increases, the topography profile becomes rougher and grain formation becomes evident. AFM topography analysis of different film thickness suggests that growth dynamics changes from FM to a Stranski-Krastanov mode (SK: layer-plus-island) and finally to a 3-d island growth regime. The relatively quick transformation from a strained to nearly no strained form of thin film growth is apparently induced by the relatively large mismatch of the STO and NiMnIn unit cell parameters. In spite of the lower lattice mismatch, films grown on the $\mathrm{MgO}$ substrate tend to form $3 \mathrm{~d}$-islands noticeably sooner. This may be due to a different surface-ad-atom interaction potential, but the possibility of random nucleation due to the higher defect density of the $\mathrm{MgO}$ substrate cannot be excluded. For both substrates, an increase of temperature leads to rougher films. While this is an indicator that the growth parameters, such as growth rate and substrate temperatures should be further optimized for thicker film synthesis, we will focus our attention on the films with thicknesses less than $10 \mathrm{~nm}$, where we can safely assume the domination of substrate-induced strained films in the magnetic response.

The room temperature XRD analysis clearly indicates the presence of Ni-Mn-In phases for films grown on both the STO and $\mathrm{MgO}$ substrates (Fig. 2). In both cases, the films were found to be textured along the $\langle 220\rangle$ directions. X-ray patterns identify the structures of the $\mathrm{MgO}$-grown Heusler alloys as cubic (austenitic) and tetragonal (martensitic) mixed phases that can be described by the cell parameters $a_{C}=5.96 \AA$, and $a_{T}=5.82 \AA$, and $c_{T}=6.74 \AA$ for cubic and tetragonal phases, respectively. It is interesting to note that, while the cubic parameter $a_{C}$ is slightly larger than $\sqrt{2} \times \mathrm{MgO}$ cell parameter, the tetragonal parameter $a_{T}$ is smaller. Therefore, in the case of $\mathrm{MgO}$, it seems that it is energetically favorable for the mixed phase lattice parameters to have values close to those of the substrate.

In contrast, peaks from the cubic phase have not been detected in the case of the STO-grown films; the observed XRD patterns (see Figure 2) suggest the presence of a single tetragonal phase at ambient temperature with unit cell parameters $a_{T}=5.48 \AA$ and $c_{T}=6.14 \AA$. In this case, $a_{T}$ deviated

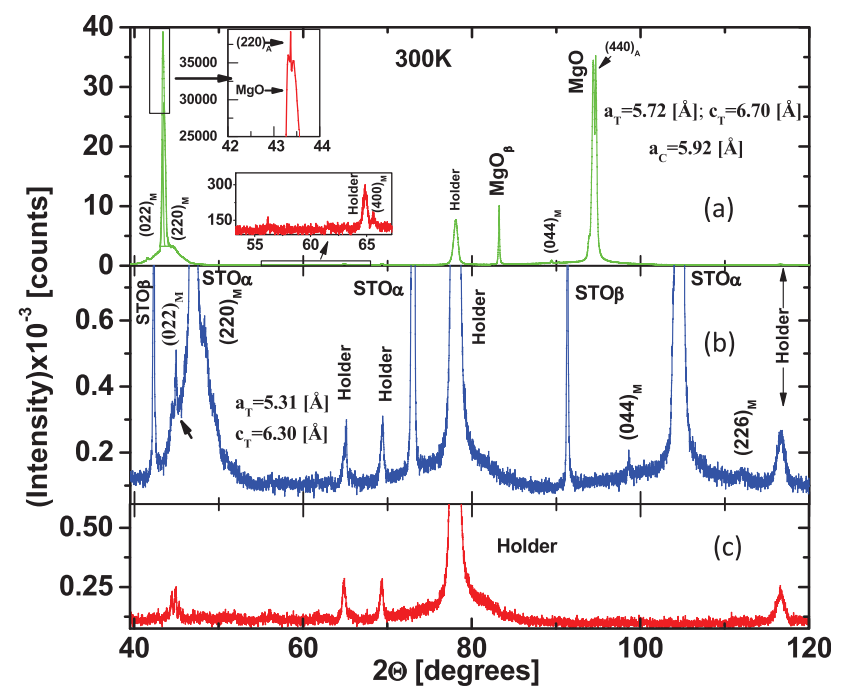

FIG. 2. Room temperature XRD patterns of $\mathrm{Ni}_{50} \mathrm{Mn}_{35} \mathrm{In}_{15}$ thin films grown on (a) $\mathrm{MgO}$ and (b) $\mathrm{SrTiO}_{3}$ substrates, and (c) the sample holder. The peaks can be identified as being from a cubic/austenitic Heusler alloy structure ((hkl) marked by index "A"), plus a tetragonal/martensitic phase ((hkl) marked by index "M") for films grown on $\mathrm{MgO}$. Only a martensitic phase was observed for films grown on STO.

from $\sqrt{2} \times$ STO cell parameter by $0.7 \%$. Obtained lattice parameters are significantly smaller when compared to those observed in the $\mathrm{MgO}$ and bulk compounds, confirming the formation of compressively strained film induced by corresponding lattice mismatch.

The coexistence of the high- and low-temperature crystal phases for films grown on the $\mathrm{MgO}$ substrate is evidence of the presence of a temperature-induced first order structural transition close to $300 \mathrm{~K}$. Indeed, we found (see Fig. 3) that the $\mathrm{M}(\mathrm{T})$ curve of the tensile-strained $\mathrm{MgO}$-grown film is very similar to those observed for bulk off-stoichiometric NiMnIn alloys. ${ }^{9}$ As the temperature increases, the first sharp magnetization decrease is observed at $\mathrm{T}_{\mathrm{CM}}=286 \mathrm{~K}$, indicating a magnetic second order phase transition in the martensitic phase. At $\mathrm{T}_{\mathrm{A}}=321 \mathrm{~K}$, a first order phase transition associated with the onset of the austenite phase is observed. At this temperature, the magnetization sharply increases and then falls again at the Curie temperature in the vicinity of

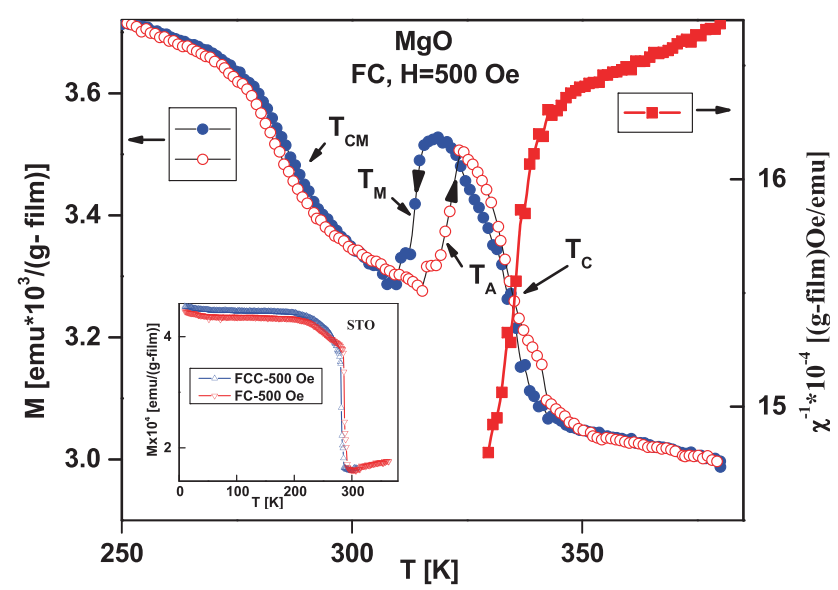

FIG. 3. (Left panel) Magnetization vs. temperature for $\mathrm{Ni}_{50} \mathrm{Mn}_{35} \mathrm{In}_{15} 10 \mathrm{~nm}$ thin films grown on $\mathrm{MgO}$ and STO (inset) single crystal substrates. (Right panel) Temperature dependence of the inverse susceptibility for the film grown on $\mathrm{MgO}$. 
$\mathrm{T}_{\mathrm{C}}=334 \mathrm{~K}$. While the cooling cycle repeats, the martensitic phase re-establishes at $\mathrm{T}_{\mathrm{M}}=313 \mathrm{~K}$, yielding a $8 \mathrm{~K}$ temperature hysteresis, confirming that the phase transition is of first order. The inverse susceptibility increases linearly with increasing temperature in interval $\mathrm{T}>334 \mathrm{~K}$ (Fig. 3), confirming the paramagnetic state of the sample above $334 \mathrm{~K}$.

A different $\mathrm{M}(\mathrm{T})$ scenario was observed for compressively strained STO-grown films. Only one sharp magnetization drop was observed near $300 \mathrm{~K}$. Taking into account the presence of a low-symmetry phase from X-ray analysis, we can conclude that this magnetization drop originates from a magnetic transformation inside the martensitic phase. We did not observe an indication of a first order magnetic phase transition with large hysteresis-a characteristic signature of an austenitic transformation in NiMnIn Heusler alloys. It is likely that $T_{M}$ and $T_{C}$ are higher than $400 \mathrm{~K}$ (upper limit of the measured temperature interval) in our compressively strained films. If we consider the martensitic transformation as a tetragonal distortion of the cubic-phase film, then it is possible to assume that the preferential axis of such a deformation would be sensitive to the strain induced on the basal plane. The difference between the preferred distortion axes of films grown on $\mathrm{MgO}$ and STO can be easily inferred from the magnetization curves taken in the martensitic phase (Fig. 4). It is clearly seen that the MgO-based nearly relaxed film results in out-of plane anisotropy, while the STO-grown samples have a slight in-plane anisotropy. Such a drastic anisotropy change is striking enough but could be understood considering the extreme sensitivity of off-stochiometric Heusler alloys to changes in electronic structure, ionic microstructure, and strain distribution. ${ }^{24}$

In conclusion, we have successfully synthesized high quality thin films from a $\mathrm{Ni}_{50} \mathrm{Mn}_{35} \mathrm{In}_{15}$ Heusler alloy target using pulsed laser deposition. Nearly relaxed thin films consisting of a cubic and tetragonal phase mixture were grown on $\mathrm{MgO}\langle 001\rangle$ single crystal substrates, and compressively

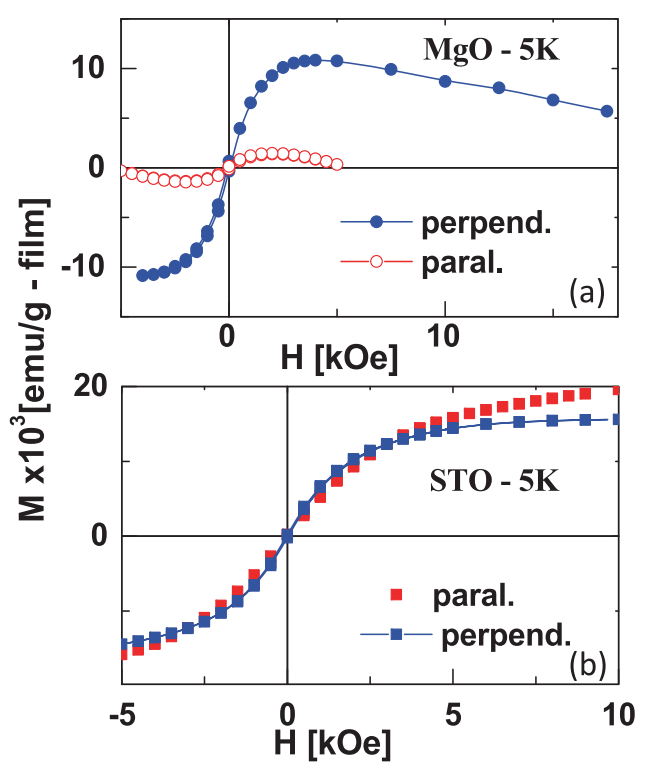

FIG. 4. Magnetization vs. applied field at $\mathrm{T}=5 \mathrm{~K}$ (see text). $\mathrm{MgO}$-grown films show out-of-plane anisotropy, whereas STO-grown films reveal a slight in-plane anisotropy. strained epitaxial-like films were grown on $\mathrm{SrTiO}_{3}\langle 001\rangle$. $\mathrm{X}$-ray and thermomagnetic measurements indicated the presence of a martensitic-like transition in the case of $\mathrm{MgO}$ at about $315 \mathrm{~K}$, between the ferromagnetic austenitic and low magnetization state of the martensitic phase, similar to that observed in off-stoichiometric bulk Ni-Mn-In Heusler alloys with approximately 15 at. \% In concentration. Finally, we have found that compressive strain from growth on STO stabilizes the martensitic phase.

Work at the University of Nebraska was supported by the National Science Foundation (NSF) through Nebraska MRSEC (DMR-0820521). The SIUC and LSU team was supported by the Office of Basic Energy Sciences, Material Science Division of the U.S. Department of Energy (Grant No. DE-FG02-06ER46291).

${ }^{1}$ I. Dubenko, T. Samanta, A. Kumar Pathak, A. Kazakov, V. Prudnikov, S. Stadler, A. Granovsky, A. Zhukov, and N. Ali, J. Magn. Magn. Mater. 324, 3530 (2012).

${ }^{2}$ E. Liu, W. Wang, L. Feng, W. Zhu, G. Li, J. Chen, H. Zhang, G. Wu, C. Jiang, H. Xu, and F. de Boer, Nat. Commun. 3, 873 (2012).

${ }^{3}$ C. H. Yu, L. Q. Meng, J. L. Chen, F. M. Yang, S. R. Qi, W. S. Zhan, Z. Wang, Y. F. Zheng, and L. C. Zhao, Appl. Phys. Lett. 75, 2990 (1999).

${ }^{4}$ R. Kainuma, Y. Imano, W. Ito, Y. Sutou, H. Morito, S. Okamoto, O. Kitakami, K. Oikawa, A. Fujita, T. Kanomata, and K. Ishida, Nature 439, 957 (2006).

${ }^{5}$ M. Khan, I. Dubenko, S. Stadler, and N. Ali, J. Phys.: Condens. Matter 20, 235204 (2008).

${ }^{6}$ A. K. Pathak, I. Dubenko, Y. Xiong, P. W. Adams, S. Stadler, and N. Ali, IEEE Trans. Magn. 46, 1444 (2010)

${ }^{7}$ I. Dubenko, A. K. Pathak, S. Stadler, N. Ali, Ya. Kovarskii, V. N. Prudnikov, N. S. Perov, and A. B. Granovsky, Phys. Rev. B 80, 092408 (2009).

${ }^{8}$ T. Krenke, E. Duman, M. Acet, E. F. Wassermann, X. Moya, L. Mañosa, and A. Planes, "Inverse magnetocaloric effect in ferromagnetic Ni-Mn-Sn alloys," Nature Mater. 4, 450 (2005).

${ }^{9}$ A. K. Pathak, M. Khan, I. Dubenko, S. Stadler, and N. Ali, Appl. Phys. Lett. 90, 262504 (2007).

${ }^{10}$ I. Dubenko, M. Khan, A. K. Pathak, B. R. Gautam, S. Stadler, and N. Ali, J. Magn. Magn. Mater. 321, 754 (2009).

${ }^{11}$ H. E. Karaca, I. Karaman, B. Basaran, Y. Ren, Y. I. Chumlyakov, and H. J. Maier, Adv. Funct. Mater. 19, 983 (2009).

${ }^{12}$ N. Sarawate and M. Dapino, Appl. Phys. Lett. 88, 121923 (2006).

${ }^{13}$ I. Karaman, B. Basaran, H. E. Karaca, A. I. Karsilayan, and Y. I. Chumlyakov, Appl. Phys. Lett. 90, 172505 (2007).

${ }^{14}$ K. A. Gschneidner, Jr., V. K. Pecharsky, and A. O. Tsokol, Rep. Prog. Phys. 68, 1479 (2005).

${ }^{15}$ T. Krenke, M. Acet, E. F. Wassermann, X. Moya, L. Mañosa, and A. Planes, "Ferromagnetism in the austenitic and martensitic states of Ni-MnIn alloys," Phys. Rev. B 73, 174413 (2006).

${ }^{16}$ J. Dubowik, Y. Kudryavtsev, Y. P. Lee, N. N. Lee, and B. S. Hong, Mol. Phys. Rep. 40, 55 (2004).

${ }^{17}$ M. Kurfi, B. Schultz, R. Anton, G. Meier, L. Sawilski, and J. Kotzler, J. Magn. Magn. Mater. 290-291, 591 (2005).

${ }^{18}$ B. Bohse, A. Zolotaryov, W. Kreuzpaintner, D. Lott, A. Kornowski, A. Stemmann, Ch. Heyn, and W. Hansen, J. Cryst. Growth 323, 368 (2011).

${ }^{19}$ A. Grunin, A. Goikhman, and V. Rodionova, Solid State Phenom. 190, 311 (2012).

${ }^{20}$ A. Hakola, O. Heczko, A. Jaakkola, T. Kajava, and K. Ullakko, Appl. Phys. A 79, 1505 (2004).

${ }^{21}$ R. Niemann, O. Heczko, L. Schultz, and S. Fähler, Appl. Phys. Lett. 97, 222507 (2010).

${ }^{22}$ R. Niemann, L. Schultz, and S. Fähler, J. Appl. Phys. 111, 093909 (2012).

${ }^{23}$ W. Ito, K. Ito, R. Y. Umetsu, R. Kainuma, K. Koyama, K. Watanabe, A. Fujita, K. Oikawa, K. Ishida, and T. Kanomata, Appl. Phys. Lett. 92, 021908 (2008).

${ }^{24}$ S. Roy, E. Blackburn, S. M. Valvidares, M. R. Fitzsimmons, S. C. Vogel, M. Khan, I. Dubenko, S. Stadler, N. Ali, S. K. Sinha, and J. B. Kortright, Phys. Rev. B 79, 235127 (2009). 